\title{
Evaluation of the XTAG Gastrointestinal Pathogen Panel Assay for the Detection of Enteric Pathogens in Kuwait
}

\author{
Manuel John Albert Vincent Olubunmi Rotimi Jamshed lqbal \\ Wassim Chehadeh \\ Department of Microbiology, Faculty of Medicine, Kuwait University, Jabriya, Kuwait
}

\section{Key Words}

xTAG gastrointestinal pathogen panel assay · Enteric pathogens · Diarrhea $\cdot$ Kuwait

\begin{abstract}
Objective: To evaluate the utility of the Luminex XTAG gastrointestinal pathogen panel (GPP) assay in the detection of enteric pathogens from diarrheal stool samples in Kuwait. Materials and Methods: The Luminex XTAG GPP assay was used according to the manufacturer's instructions to evaluate single diarrheal stool samples from 109 hospitalized patients at Mubarak Al-Kabeer Hospital, Kuwait, from March 2014 to June 2015. The assay procedure involved nucleic acid extraction from stool samples, amplification of the target by reverse transcriptase polymerase chain reaction, hybridization of the amplified target by probe, detection of the target by the Luminex instrument and computerized data analysis. Conventional microbiological assays were used as the gold standard for comparison. Results: From the 109 diarrheal stool samples, $20(18.4 \%)$ pathogens were detected by the XTAG GPP assay compared to 10 (9.2\%) pathogens using conventional assays. Both methods detected 3 Salmonella spp., 3 Clostridium difficile, 2 rotavirus and 2 norovirus. In addition,
\end{abstract}

the xTAG GPP assay detected 1 Shigella sp., 6 Campylobacter spp., 1 Cryptosporidium sp. and 2 Giardia lamblia which were missed by conventional assays. Conclusions: In this study, XTAG GPP detected twice as many pathogens as the conventional assays. We recommend the introduction of this assay in routine diagnostic laboratories for a rapid and better diagnosis and treatment of diarrheal disease.

(C) 2016 S. Karger AG, Basel

\section{Introduction}

Diarrheal disease is a major health problem, with approximately 1.7 billion cases reported globally each year [1]. It is also a leading cause of malnutrition and the second leading cause of death in children under 5 years of age, killing approximately 760,000 of them each year [1]. The economic cost of treatment of diarrhea is also considerable [2]. Diarrheal disease is caused by a variety of pathogens including bacteria, parasites and viruses. Accurate identification of diarrheal agents is necessary for provision of appropriate therapy and containment of outbreaks. However, conventional microbiology for the diagnosis of diarrhea is time-consuming, requires up to 2-3

Prof. Manuel John Albert

Department of Microbiology, Faculty of Medicine, Kuwait University PO Box 24923

Safat 13110 (Kuwait)

E-Mail John@ @sc.edu.kw 
days to get all the results (even though microscopy for ova and parasites is fast, bacterial culture is delayed), laborintensive involving multiple techniques (microscopy, culture, immunological assay) and hampered by low sensitivity [3]. On the other hand, molecular biological techniques based on the detection of specific nucleic acid sequences are rapid and more sensitive [2]. Many molecular tests have been published for enteric pathogens $[4,5]$; however, they mostly detected few pathogens, were developed in-house and have not undergone extensive evaluation $[4,5]$. Hence, multiplex tests that detect several pathogens in a single assay are desirable. One such test is the xTAG [gastrointestinal pathogen panel (GPP) assay, a multiplexed molecular test marketed by Luminex Corporation (Austin, Tex., USA)]. This assay detects up to 15 different pathogens responsible for $>90 \%$ of infectious diarrhea from human stool samples with a turnaround time of about $5 \mathrm{~h} \mathrm{[6].} \mathrm{The} \mathrm{pathogens} \mathrm{detected} \mathrm{are:} \mathrm{bacteria}$ (Salmonella spp., Shigella spp., Vibrio cholerae, Yersinia enterocolitica, Campylobacter spp., Clostridium difficile, Escherichia coli O157, Shiga toxin-producing E. coli and enterotoxigenic $E$. coli), viruses (rotavirus A, adenovirus 40/41 and norovirus GI/GII) and parasites (Cryptosporidium spp., Entamoeba histolytica and Giardia lamblia). Hence, the primary objective of the study was to evaluate the utility of this assay in Kuwait. Furthermore, since the last comprehensive study on the etiology of diarrhea in Kuwaiti in the 1980s [7], many diarrheal pathogens have been discovered [8]. Hence, a secondary objective of the study was to evaluate the relative distribution of various etiological agents detected by the xTAG GPP assay in diarrheal stool samples.

\section{Materials and Methods}

\section{Collection of Diarrheal Stool Samples}

Consecutive diarrheal stool samples from patients hospitalized at Mubarak Al-Kabeer Hospital, Kuwait (one sample per patient of any age group) received at the Clinical Microbiology Laboratory of Mubarak Al-Kabeer Hospital from March 2014 to June 2015 were used for evaluation. Specimens were collected $<48 \mathrm{~h}$ after hospitalization of patients.

\section{Luminex xTAG GPP Assay}

This assay was performed on thawed stool samples frozen at $-70^{\circ} \mathrm{C}$ as per the manufacturer's instructions. Nucleic acid was extracted from pretreated stool samples by the NucliSENS Easy MAG system (bioMerieux, Marcy l'Etoile, France). The xTAG GPP assay included an RNA-based internal control (MS2 bacteriophage) to monitor the entire assay performance. The other steps involved reverse transcription polymerase chain reaction (RTPCR) and subsequent hybridization. The PCR amplification was performed using a GeneAmp PCR system 9700 thermal cycler (Applied Biosystems, Forster City, Calif., USA) with the recommended cycling parameters. The data were acquired with the Luminex MagPix analyzer, and data analysis was carried out using TDAS data analysis software. The results obtained using conventional assays were not revealed until the xTAG GPP assay was completed.

\section{Conventional Assays}

Bacteria. Detection of Salmonella spp., Shigella spp. and $V$. cholerae was done by methods described previously [9], with a minor modification. Instead of taurocholate-tellurite-gelatin agar, thiosulfate-citrate-bile salt-sucrose (TCBS) agar was used for culturing vibrios. Briefly, fresh stool specimens were cultured on MacConkey agar (Oxoid, Basingstoke, UK), Salmonella-Shigella (SS) agar (Oxoid), TCBS agar (Eiken, Tokyo, Japan), CampyBAP agar (Becton-Dickinson, Franklin Lakes, N.J., USA) and in Selenite F broth (Oxoid). All media except CampyBAP were incubated in an ambient atmosphere at $37^{\circ} \mathrm{C}$ for $24 \mathrm{~h}$. Selenite F broth was subcultured onto SS agar, after which the agar medium was incubated for $24 \mathrm{~h}$ as described above. CampyBAP agar was incubated at $42^{\circ} \mathrm{C}$ for $48 \mathrm{~h}$ in a microaerobic atmosphere. Characteristic, lactose-nonfermenting pale colonies on the MacConkey agar and SS agar were screened for Salmonella spp. and Shigella spp. by Kligler's iron agar (Oxoid) and subsequently by API-20 E biochemical strip (bioMerieux). Sucrose-fermenting yellow colonies on TCBS agar were screened for vibrios by biochemical reactions as described above. If biochemical reactions were suggestive, Salmonella spp., Shigella spp. and V. cholerae O1 and O139 were confirmed by slide agglutination test with specific antisera (DenkaSeiken, Tokyo, Japan). Suspected Campylobacter spp. colonies on CampyBAP were confirmed by characteristic morphology on Gram stain and motility as well as by positive oxidase and catalase tests. Entire nonmucoid lactose-fermenting colonies resembling $E$. coli from the MacConkey agar were stored in Luria broth with $30 \%$ glycerol at $-70^{\circ} \mathrm{C}$ until tested for selected categories of diarrheagenic E. coli [10]. C. difficile was detected directly in stool samples by the Xpert ${ }^{\circledR} C$. difficile (Cephid, Sunnyvale, Calif., USA) assay which detects genes encoding cytotoxin B and binary toxin. Since $Y$. enterocolitica infection is extremely rare in Kuwait, this pathogen was not searched for.

Parasites. G. lamblia and E. histolytica were detected by light microscopy of wet amount after formalin-ethyl acetate sedimentation concentration of parasites in the stool using the FPC Fecal Parasite Concentrator kit (Evergreen, Vernon, Calif., USA). Cryptosporidium spp. was detected by cold acid-fast staining of stool smear [11].

Viruses. Group A rotavirus was detected by enzyme-linked immunosorbent assay using the Premier rotaclone kit (Meridian Bioscience, Cincinnati, Ohio, USA). Noroviruses (groups I and II) were detected by RT-PCR [12], and enteric adenoviruses 40/41 (group F) by PCR [13].

\section{Statistics}

The sensitivity of the xTAG GPP assay was calculated by comparison of pathogen yield with that of conventional assays. For example, if the pathogen yield of conventional assays is $1 \mathrm{n}$ and that of the xTAG GPP assay is $2 \mathrm{n}$, with the sensitivity of the conventional assays being $100 \%$, the sensitivity of the xTAG GPP assay is $2 \mathrm{n} \times 100 / 1 \mathrm{n}=200 \%$. 
Table 1. Pathogens identified by the Luminex xTAG GPP assay and conventional assays from 109 diarrheal stool samples

\begin{tabular}{|c|c|c|}
\hline \multirow[t]{2}{*}{ Pathogen } & \multicolumn{2}{|c|}{ Number of positive samples by } \\
\hline & $\begin{array}{l}\text { xTAG GPP } \\
\text { assay }\end{array}$ & $\begin{array}{l}\text { conventional } \\
\text { assays }\end{array}$ \\
\hline Salmonella spp. & 3 & 3 \\
\hline Shigella sp. & 1 & 0 \\
\hline Campylobacter spp. & 6 & 0 \\
\hline C. difficile & 3 & 3 \\
\hline Rotavirus & 2 & 2 \\
\hline Norovirus & 2 & 2 \\
\hline Cryptosporidium sp. & 1 & 0 \\
\hline G. lamblia & 2 & 0 \\
\hline Total & 20 & 10 \\
\hline
\end{tabular}

\section{Results}

The pathogens detected are shown in table 1. From the 109 stool samples, 20 (18.4\%) pathogens were detected by the xTAG GPP assay, compared to 10 (9.2\%) pathogens using conventional methods from 19 patients. Among these 19 patients, $9(8.3 \%)$ had identical pathogens (a total of 10) detected by both methods. These pathogens included Salmonella spp., C. difficile, rotavirus and norovirus in 2 patients each and a Salmonella sp. and C. difficile in 1 patient. In addition, 10 (9.2\%) patients were positive for single pathogens using the xTAG GPP assay only. These pathogens included: Shigella sp. (1 patient), Campylobacter spp. (6 patients), Cryptosporidium sp. (1 patient) and G. lamblia (2 patients). The pathogens not detected by conventional assays were Shigella sp., Campylobacter spp., Cryptosporidium spp. and G. lamblia.

Using conventional assays which are considered to be the gold standard, 10 pathogens were detected, while twice as many pathogens (20 pathogens) were detected using the xTAG GPP assay, showing its superiority.

\section{Discussion}

In this study, both the xTAG GPP assay and the conventional methods detected 3 Salmonella spp., 3 C. difficile, 2 rotavirus and 3 norovirus out of 109 diarrheal stool samples. The XTAG GPP assay detected additional pathogens that were missed by the conventional methods. These pathogens included 1 Shigella sp., 6 Campylobacter spp., 1 Cryptosporidium sp. and 2 G. lamblia. Thus, the sensitivity of the xTAG GPP assay in our study was $200 \%$.
Several independent studies have evaluated the performance of the xTAG GPP assay. In these studies, the sensitivity by diagnostic accuracy test varied from 92 to $100 \%$ [14-18]. However, since the additional positives detected by the xTAG GPP assay were proven to be true positives by alternative tests, in fact, the true sensitivity of the xTAG GPP assay (as defined in our study) in these evaluations exceeded $100 \%$.

In this study, 9.2\% enteric pathogens detected in diarrheal stool samples by conventional methods was similar to $10 \%$ of enteric pathogens detected in diarrheal stool sampes by conventional methods in routine diagnostic laboratories [19-21]. In our study, the use of the xTAG GPP assay has improved the yield of pathogens by 2 -fold, detecting an additional 10 pathogens, which is similar to the results of other studies [14, 18, 22-24]. Conventional methods are known to be less sensitive than molecular methods for the detection of pathogens [2]. Our study also revealed a wide spectrum of pathogens in diarrheal cases in Kuwait. Additional pathogens detected in this study compared to the previous study in Kuwait were C. difficile, norovirus and Cryptosporidium sp. [7].

The xTAG GPP assay was also found to report pathogens for which tests were not requested by physicians $[25,26]$. Conventional assays missed etiological agents in some diarrheal cases, and these cases were judged as diarrheas of unknown etiologies. However, the xTAG GPP assay did detect pathogens in these cases, which were Salmonella spp., Campylobacter spp. and Cryptosporidium spp. [22]. The identification of coinfections is necessary as it can help guide the most appropriate pathogen-specific therapy. In our study, only 1 patient had a coinfection - C. difficile with a Salmonella sp. However, both conventional and xTAG GPP assays detected these pathogens. The xTAG GPP assay has dramatically improved the diagnosis of coinfections as compared to conventional tests. The detection of coinfections varied from 7 to $38 \%$ in stool specimens by the XTAG GPP assay, whereas by conventional methods, it was either zero or negligible $[14,22,23,26]$. Although C. difficile was found to have the highest involvement in coinfections, it is not clear whether it represents infection or colonization [14]. Our testing was carried out on inpatients of all age groups. The clinical utility of the XTAG GPP assay has been proven in a variety of patient groups and settings. These include adult and pediatric patients $[16,22]$, immunocompromised and transplant patients $[22,26]$, outpatients $[16]$, travelers $[16,22]$, outbreak situations $[27,28]$ as well as epidemiology and monitoring situations [23, 28]. 
Testing in pediatric patients with diarrhea revealed the usual array of pathogens expected in this age group, with rotavirus predominating [16]. Application of this test in travelers with diarrhea showed the major pathogens to be Shigella spp., enterotoxigenic E. coli, enteroaggregative E. coli and G. lamblia. Regional variation in the prevalence of enterotoxigenic E. coli was found [23]. The test also detected pathogens not found by conventional methods or not requested for testing. Thus, the test allowed a better assessment of the etiology of travelers' diarrhea [23]. In transplant patients, diarrhea used to be attributed to adverse effects of immunosuppressive therapy. However, using the xTAG GPP assay, diarrheal pathogens were detected in most kidney transplant patients studied, with norovirus as the leading cause [26]. xTAG GPP was used to detect outbreak pathogens in the German outbreak of bloody diarrhea and hemolytic uremic syndrome due to the novel enterohemorrhagic $E$. coli O104:H4 positive for Stx 1 [27], as well as in the cholera epidemic in Haiti [28]. In both these outbreaks, the causative agents were correctly identified. With xTAG GPP, there is a shorter hands-on time, high throughput detection of multiple enteric pathogens, improved turnaround time, consolidated laboratory workflow and simplified stool culture practices which reduce the overall cost of laboratory investigation [17]. With a 5-hour turnaround time, it has the potential to optimize patient management and infection control practices and reduce overall hospital costs [14, 24]. However, there are some disadvantages of the xTAG GPP assay: (1) since the luminex platform uses an open system, samples are prone to amplicon contamination unless good laboratory practices are followed, and (2) conventional bacterial culture and parasitological examination are still required to de- tect other pathogens and to determine antimicrobial susceptibility in specific cases.

Thus, the xTAG GPP assay is a rapid test with a superior sensitivity, capable of detecting up to 15 diarrheal pathogens, as well as cost-effective, considering that all 15 pathogens are detected in a single test. However, a laboratory can also select/deselect which pathogens are detected on a patient basis. The xTAG GPP in vitro diagnostic assay kit was the first multiplex molecular test cleared by the Food and Drug Administration of the United States of America for a diagnosis of diarrheal disease after extensive evaluation [29]. This also gives confidence for the introduction of the assay into the routine clinical laboratory work. One limitation of our study was that the sample size was relatively small.

\section{Conclusion}

In this study, the xTAG GPP assay detected all the pathogens also found by conventional methods as well as additional pathogens not detected using conventional methods. This assay is a multiplex molecular test for the simultaneous detection of up to 15 major diarrheal pathogens for a rapid and better diagnosis that might lead to appropriate treatment of diarrheal disease. Our results and those of other studies suggest that this assay can be used in different settings and countries.

\section{Acknowledgements}

We thank Luminex Molecular Diagnostics Inc. for providing the reagents used in this study and Fatima Alattar for her help with the study.

\section{References}

1 WHO: Diarrhoeal disease. Fact sheet No. 330 2014. http://www.who.int/mediacentre/factsheets/fs330/en/index.html.

-2 Amar CFL, East CL, Gray J, et al: Detection by PCR of eight groups of enteric pathogens in 4,627 faecal samples: re-examination of the English case-control Infectious Intestinal Disease Study (1993-1996). Eur J Clin Microbiol Infect Dis 2007;26:311-323.

3 Platts-Mills JA, Liu J, Houpt ER: New concepts for diagnostics in infectious diarrhea. Mucosal Immunol 2013;6:876-885.

4 de Boer RF, Ott A, Kesztyus B, et al: Improved detection of five major gastrointestinal pathogens by use of a molecular screening approach. J Clin Microbiol 2010;48:4140-4146.
5 Fujioka M, Kasai K, Miura T, et al: Rapid diagnostic method for the detection of diarrheagenic Escherichia coli by multiplex PCR. Jpn J Infect Dis 2009;62:476-480.

6 Luminex xTAG Gastrointestinal Pathogen Panel. http://www.luminexcorp.com/clini$\mathrm{cal} /$ infectious-disease/gastrointestinalpathogen-panel/.

7 Sethi SK, Khuffash FA, Al-Nakib W: Microbial etiology of acute gastroenteritis in hospitalized children in Kuwait. Pediatr Infect Dis J 1989;8:593-597.

8 Taniuchi M, Sobuz SU, Begum S, et al: Etiology of diarrhea in Bangladeshi infants in the first year of life analyzed using molecular methods. J Infect Dis 2013;208:1794-1802. $\checkmark 9$ Albert MJ, Faruque ASG, Faruque SM, et al: Case-control study of enteropathogens associated with childhood diarrhea in Dhaka, Bangladesh. J Clin Microbiol 1999;37:3458-3464.

10 Albert MJ, Rotimi VO, Dhar R, et al: Diarrhoeagenic Escherichia coli are not a significant cause of diarrhoea in hospitalised children in Kuwait. BMC Microbiol 2009;9:62.

11 Iqbal J, Hira PR, Al-Ali F, et al: Cryptosporidiosis in Kuwaiti children: seasonality and endemicity. Clin Microbiol Infect 2001;7: 261-266.

12 Al-Rashidi A, Chehadeh W, Szucs GG, et al: Different norovirus genotypes in patients with gastroenteritis in Kuwait. J Med Virol 2013;85:1611-1618. 
13 Xu W, McDonough M, Erdman DD: Speciesspecific identification of human adenoviruses by a multiplex PCR assay. J Clin Microbiol 2000;38:4114-4120.

14 Claas EC, Burnham CD, Mazzulli T, et al: Performance of the xTAG gastrointestinal pathogen panel, a multiplex molecular assay for simultaneous detection of bacterial, viral, and parasitic causes of infectious gastroenteritis. J Microbiol Biotechnol 2013;23:1041-1045.

15 Luminex Molecular Diagnostics, Inc: xTAG gastrointestinal pathogen panel package insert IVD. MLD-032-KPI-001 Rev C. 2014

-16 Beckmann C, Heininger U, Marti H, et al: Gastrointestinal pathogens detected by multiplex nucleic acid amplification testing in stools of pediatric patients and patients returning from the tropics. Infection 2014;42: 961-970.

17 Patel A, Navidad J, Bhattacharya S: Site-specific clinical evaluation of the Luminex xTAG gastrointestinal pathogen panel for detection of infectious gastroenteritis in fecal specimens. J Clin Microbiol 2014;52:3068-3071.

18 Perry MD, Corden SA, Howe RA: Evaluation of the Luminex xTAG Gastrointestinal Pathogen Panel and the Savyon Diagnostics Gastrointestinal Infection Panel for the detection of enteric pathogens in clinical samples. J Med Microbiol 2014;63:1419-1426.
19 Johnston SP, Ballard MM, Beach MJ, et al: Evaluation of three commercial assays for detection of Giardia and Cryptosporidium organisms in fecal specimens. J Clin Microbiol 2003;41:623-626.

20 Voetsch AC, Angulo FJ, Rabatsky-Ehr T, et al: Laboratory practices for stool-specimen culture for bacterial pathogens, including Escherichia coli $\mathrm{O} 157: \mathrm{H} 7$ in the FoodNet sites, 1995-2000. Clin Infect Dis 2004;38(suppl 3):S190-S197.

21 Fotedar R, Stark D, Beebe N, et al: PCR detection of Entamoeba histolytica, Entamoeba dispar, and Entamoeba moshkovskii in stool samples from Sydney, Australia. J Clin Microbiol 2007;45:1035-1037.

22 Mengelle C, Mansury JM, Prere MF, et al: Simultaneous detection of gastrointestinal pathogens with a multiplex Luminex-based molecular assay in stool samples from diarrhoeic patients. Clin Microbiol Infect 2013; 19:E458-E465.

23 Zboromyrska Y, Hurtado JC, Salvador P, et al: Aetiology of traveller's diarrhoea: evaluation of a multiplex PCR tool to detect different enteropathogens. Clin Microbiol Infect 2014; 20:O753-O759.
24 Goldenberg SD, Bacelar M, Brazier P, et al: A cost benefit analysis of the Luminex xTAG Gastrointestinal Pathogen Panel for detection of infectious gastroenteritis in hospitalised patients. J Infect 2015;70:501-511.

25 Kahlau P, Malecki M, Schildgen V, et al: Utility of two novel multiplexing assays for the detection of gastrointestinal pathogens - a first experience. Springerplus 2013;2:106.

26 Coste JF, Vuiblet V, Moustapha B, et al: Microbiological diagnosis of severe diarrhea in kidney transplant recipients by use of multiplex PCR assays. J Clin Microbiol 2013;51: 1841-1849.

27 Malecki M, Schildgen V, Kamm M, et al: Rapid screening method for multiple gastroenteric pathogens also detects novel enterohemorrhagic Escherichia coli O104:H4. Am J Infect Control 2012;40:82-83.

28 Valcin CL, Severe K, Riche CT, et al: Predictors of disease severity in patients admitted to a cholera treatment center in urban Haiti. Am J Trop Med Hyg 2013;89:625-632.

29 Navidad J, Griswold DJ, Gradus MS, et al: Evaluation of Luminex xTAG gastrointestinal pathogen analyte-specific reagents for high throughput, simultaneous detection of bacteria, viruses and parasites of clinical and public health importance. J Clin Microbiol 2013;51: 3018-3024 